\title{
THE CONTRIBUTION OF EDUCATION AND TEACHING EXPERIENCE TO THE PROFESSIONALISM OF SDLB TEACHERS
}

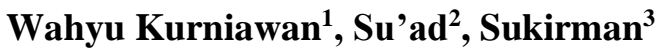 \\ 1,2,3 Universitas Muria Kudus, Kudus, Indonesia \\ 1wahyu_kudus08@yahoo.co.id, ${ }^{2}$ suad@umk.ac.id, ${ }^{3}$ sukirman@umk.ac.id
}

\begin{abstract}
Teachers of Special Schools (SLB) are demanded to have professionalism in teaching. The teachers' professionalism represents the commitment of teachers to improve their professional abilities and to develop their skills in carrying out their duties and functions as teachers. This study aimed to determine the effect of education, training, and teaching experience on teachers' professionalism of special elementary school (SDLB) teachers in Kabupaten Kudus. This study was an explanatory research with a quantitative approach. The research subjects were 63 SDLB teachers in Kabupaten Kudus. The samples were selected through total sampling technique. The data were collected through a questionnaire and were analzed by using multiple regression analysis. The results showed that education partially had a positive and significant effect on the professionalism of SDLB teachers in Kabupaten Kudus. Similarly, teaching experience partially gave a positive and significant effect on the professionalism of SDLB teachers in Kabupaten Kudus. Overall, this study found that both education and teaching experience had a positive and significant effect on the professionalism of SDLB teachers. This was supported by the result of the coefficient of determination (R2) of 0.645 showing that the influence of education and teaching experience on teacher professionalism was $64.5 \%$. moreover, teaching experience had the greatest influence on teachers professionalism for $55.4 \%$ while the effect of education was $9.1 \%$. This study concluded that the professionalism of SDLB teachers in Kabupaten Kudus could be increased by providing more teaching experience and trainings as an effort to improve teachers' competence
\end{abstract}

Keywords: education, teaching experience, teacher professionalism

\section{KONTRIBUSI PENDIDIKAN DAN PENGALAMAN MENGAJAR TERHADAP PROFESIONALISME GURU SDLB}

\begin{abstract}
ABSTRAK
Guru Sekolah Luar Biasa (SLB) dituntut memiliki profesionalitas dalam mengajar. Profesionalisme guru menunjukkan komitmen guru untuk meningkatkan kemampuan profesionalnya dan mengembangkan keahliannya dalam menjalankan tugas dan fungsinya sebagai guru. Penelitian ini bertujuan untuk mengetahui pengaruh pendidikan serta pengalaman mengajar terhadap profesionalisme guru Sekolah Dasar Luar Biasa (SDLB) di Kabupaten Kudus. Penelitian ini merupakan penelitian explanatory dengan pendekatan kuantitatif. Subjek penelitian adalah guru SDLB di Kabupaten Kudus sebanyak 63 guru. Teknik pengambilan sampel dilakukan total sampling. Metode pengumpulan data menggunakan kuesioner. Analisis data menggunakan analisis regresi berganda. Hasil penelitian menunjukkan bahwa pendidikan secara parsial berpengaruh positif dan signifikan terhadap profesionalisme guru SDLB di Kabupaten Kudus. Pengalaman mengajar secara parsial berpengaruh positif dan signifikan terhadap profesionalisme guru SDLB di Kabupaten Kudus. Pendidikan dan pengalaman mengajar secara bersama-sama berpengaruh positif dan signifikan terhadap profesionalisme guru SDLB di Kabupaten Kudus. Hasil uji koefisien determinasi (R2) sebesar 0.645 menunjukkan bahwa besarnya pengaruh pendidikan dan pengalaman mengajar terhadap profesionalisme guru adalah $64.5 \%$. Pengalaman mengajar memberikan pengaruh paling besar terhadap profesionalisme guru yaitu sebesar 55.4\%, sedangkan pengaruh pendidikan sebesar $9.1 \%$. Peningkatan profesionalisme guru SDLB di Kabupaten Kudus dapat dilakukan dengan menambah pengalaman mengajar guru serta pemberian pelatihan sebagai upaya meningkatkan kompetensi guru.
\end{abstract}

Kata Kunci: pendidikan, pengalaman mengajar, profesionalisme guru

\begin{tabular}{|c|c|c|}
\hline Submitted & Accepted & Published \\
\hline 01 November 2020 & 22 Maret 2021 & 23 Mei 2021 \\
\hline
\end{tabular}

\begin{tabular}{|l|l|l|}
\hline Citation & $:$ & $\begin{array}{c}\text { Kurniawan, W., Su'ad, S., \& Sukirman, S. (2021). The Contribution of Education and Teaching Experience to the } \\
\text { Profesionalism of SDLB Teachers. Jurnal PAJAR (Pendidikan dan Pengajaran), 5(3), 599-608. DOI : } \\
\text { http://dx.doi.org/10.33578/pjr.v5i3.8198. }\end{array}$ \\
\hline
\end{tabular}




\section{PENDAHULUAN}

Pendidikan merupakan hal yang sangat penting dan tidak bisa dipisahkan dari dunia kehidupan manusia. Menurut pasal 15 dalam Undang-Undang Sistem Pendidikan Nasional Tahun 2003, pendidikan terdiri dari beberapa jenis yaitu pendidikan umum, kejuruan, akademik, profesi, vokasi, keagamaan, dan khusus. Pendidikan khusus merupakan pendidikan bagi peserta didik yang memiliki tingkat kesulitan dalam mengikuti proses pembelajaran karena kelainan fisik, emosional, mental, intelektual, sosial, dan/atau memiliki potensi kecerdasan dan bakat istimewa (Firmansyah \& Widuri, 2014).

Lembaga pendidikan SLB adalah lembaga pendidikan yang bertujuan membantu peserta didik yang menyandang kelainan fisik dan/atau mental, perilaku dan sosial agar mampu mengembangkan sikap, pengetahuan dan keterampilan sebagai pribadi maupun anggota masyarakat. Guru SLB harus mengetahui dasardasar tentang program pembelajaran, memahami karakteristik anak berkebutuhan khusus, serta bagaimana menghadapi dan melayani anak berkebutuhan khusus (Setiawan, 2018). Oleh karena itu, guru SLB dituntut memiliki profesionalitas dalam mengajar.

Profesionalisme guru dapat diartikan sebagai komitmen guru untuk meningkatkan kemampuan profesionalnya dan terus-menerus mengembangkan strategi-strategi yang digunakan dalam melakukan pekerjaan (Eliyanto \& Wibowo, 2013). Guru profesional adalah orang yang memiliki kemampuan dan keahlian khusus dalam bidang keguruan sehingga ia mampu melakukan tugas dan fungsinya sebagai guru dengan kemampuan maksimal. Setiap guru diharapkan mampu mencapai kriteria guru yang kompeten, yaitu kompetensi pedagogik, kepribadian, sosial dan profesional (Annisa,dkk., 2019).

Seorang guru yang memiliki profesionalisme yang tinggi akan tercermin pada sikap mental serta komitmennya untuk mewujudkan dan meningkatkan kualitas profesional melalui berbagai cara dan strategi.
Guru sebagai pekerja profesi, dituntut untuk selalu mengembangkan dirinya sesuai dengan tuntutan perkembangan zaman sehingga senantiasa memberikan makna profesional. Bafadal (2008) menyatakan bahwa peningkatan kualitas pendidikan di sekolah sangat dipengaruhi profesionalisme guru.

Sikap profesional juga sangat diperlukan bagi guru Sekolah Luar Biasa (SLB). Lembaga pendidikan SLB adalah lembaga pendidikan yang memiliki tujuan memberikan bantuan bagi peserta didik penyandang kelainan fisik dan/atau mental, perilaku dan sosial agar mampu mengembangkan sikap, pengetahuan dan keterampilan sebagai pribadi maupun anggota masyarakat. Guru SLB harus mengetahui dasardasar tentang program pembelajaran, memahami karakteristik anak berkebutuhan khusus, serta bagaimana menghadapi dan melayani anak berkebutuhan khusus (Setiawan, 2018). Oleh karena itu, guru SLB dituntut memiliki profesionalitas dalam mengajar. Namun, observasi yang dilakukan di SDLB di Kabupaten Kudus selama 3 bulan, diperoleh informasi antara lain: (1) guru yang memperoleh sertifikat guru profesional hanya $70 \%$, (2) guru kurang memanfaatkan hasil dari mengikuti diklat, (3) beberapa guru masih mendapatkan kesulitan dalam menghadapi anak didik.

Hasil penelitian sebelumnya oleh Setianingsih (2018) yang dilakukan pada SLB di wilayah Semarang, Surakarta, dan Boyolali menunjukkan masih adanya sikap guru SLB yang kurang profesional, misalnya guru yang memperlakukan anak berkebutuhan khusus secara diskriminasi yaitu guru masih membedabedakan latar belakang peserta didik ketika pembelajaran. Pada penelitian Firmansyah \& Widuri (2014) disebutkan bahwa terdapat guru SLB yang kesulitan dalam mengajar dan kesulitan memahami siswa, guru tersebut juga mengaku sempat mengalami stres mengajar dan bingung ketika siswanya nakal dan sulit diatur. Kondisi tersebut sangat membutuhkan kesabaran dan pengalaman yang cukup untuk menangani 
berbagai permasalahan anak berkebutuhan khusus.

Profesionalisme guru dapat dipengaruhi oleh berbagai faktor, diantaranya yaitu pendidikan, pelatihan, dan pengalaman mengajar. Pendidikan merupakan usaha yang bersifat teoritis dengan menggunakan metode tertentu, dan diarahkan kepada pemenuhan kebutuhan Ilmu Pengetahuan, kemampuan, keterampilan, keahlian, sikap dan tingkah laku (Sahari, 2015). Semakin lama seorang guru mengabdi dalam bidang pendidikan maka semakin banyak pengalaman guru. Semakin lama seorang guru menekuni bidang pekerjaannya maka seyogyanya lebih profesional dibandingkan dengan guru yang baru mengabdi (Komalasari, 2014).

Berdasarkan uraian di atas, dapat dilihat bahwa profesionalisme sangat penting dalam menjalankan tugas guru SDLB. Penelitian ini bertujuan untuk mengetahui pengaruh pendidikan, pelatihan serta pengalaman mengajar terhadap profesionalisme guru SDLB di Kabupaten Kudus.

\section{KAJIAN TEORETIS \\ Profesionalisme Guru}

Undang-Undang Nomor 14 Tahun 2005 tentang Guru dan Dosen menyatakan guru adalah pendidik profesional yang mendidik, mengajar, membimbing, mengarahkan, melatih, menilai, dan mengevaluasi peserta didik pada pendidikan anak usia dini pada jalur pendidikan formal, pendidikan dasar, dan pendidikan menengah. profesionalisme guru berarti kemampuan guru dalam menjalankan tugas-tugasnya sebagai guru yang profesional. Guru profesional harus menguasai empat standar kompetensi guru, yaitu kompetensi pedagogik, kepribadian, sosial, dan profesional.

Guru SDLB dituntut menjadi guru yang profesional dalam bidang pengetahuan anak berkebutuhan khusus. Peranan guru PLB sangat menentukan untuk mencapai tujuan mengembangkan potensi anak berkebutuhan khusus sesuai dengan kondisi dan kebutuhan anak berkebutuhan khusus. Kualitas kompetensi guru SDLB mempunyai peranan penting dalam proses interaksi belajar mengajar. Kompetensi atau kemampuan yang dimiliki guru merupakan faktor penting dalam menentukan kemampuan penguasaan pengetahuan yang telah dicapai siswa.

\section{Pendidikan}

Pendidikan merupakan suatu usaha pembentukan kepribadian dan usaha mengembangkan potensi dasar manusia supaya bagus pertumbuhan jasmani dan rohaninya, sehat badannya, waras otaknya, serta baik budi pekertinya, sehingga anak didik akan mencapai puncak kesempurnaan kepribadian sebagai manusia (Sahari, 2015). Indikator pendidikan diukur berdasarkan (UU Nomor 20 Tahun 2003, yaitu terdiri dari 1) Jenjang pendidikan dan 2) Kesesuaian pendidikan dengan pekerjaan.

Guru SDLB yang memiliki latar belakang Pendidikan Luar Biasa akan mampu merancang, melaksanakan dan mengevaluasi program bimbingan dan konseling anak berkebutuhan khusus, mampu melaksanakan manajemen kePLB-an, mampu mengembangkan kurikulum sesuai dengan kemampuan dan kebutuhan anak berkebutuhan khusus. Dengan demikian, guru tersebut mampu bekerja dalam usaha mencapai tujuan pendidikan, serta mampu melaksanakan peranannya dalam proses mengajar dan belajar pada siswa berkebutuhan khusus.

\section{Pengalaman Mengajar}

Pengalaman mengajar pada hakikatnya merupakan rangkuman dari pemahaman seseorang terhadap hal-hal yang dialami dalam mengajar, sehingga hal-hal yang dialami tersebut telah dikuasainya, baik tentang pengetahuan, keterampilan maupun nilai-nilai yang menyatu padanya (Roza, 2016). Indikator pengalaman mengajar dijelaskan oleh Rahmawati, Natsir \& Moelyono (2015) terdiri dari beberapa faktor yaitu masa kerja, tingkat pengetahuan, dan penguasaan terhadap pekerjaan.

Pengalaman mengajar guru SDLB diperoleh selama ia mengajar. Lamanya tugas sebagai seorang guru akan memberikan pengalaman yang berbeda antar guru yang satu dengan guru yang lainnya. Semakin lama dia menjabat sebagai guru, berarti semakin banyak pengalamannya, sehingga seorang guru yang 
memiliki masa kerja lama tidak akan sama dengan guru yang baru.

\section{METODE PENELITIAN}

Jenis penelitian yang digunakan dalam penelitian ini adalah penelitian penjelasan (explanatory research) dengan pendekatan kuantitatif. Penelitian dilaksanakan pada bulan Agustus sampai dengan September 2020. Populasi dalam penelitian ini yaitu seluruh guru pada lima SDLB di Kabupaten Kudus, yaitu SDLB Negeri Kaliwungu, SDLB Negeri Cendono Dawe, SDLB Negeri Purwosari, SDLB Sunan Kudus Pedawang, dan SDLB Sunan Muria Dawe. Jumlah keseluruhan guru sebanyak 63 orang. Teknik pengambilan sampel menggunakan sampling jenuh, yaitu teknik penentuan sampel dimana semua anggota populasi digunakan sebagai sampel penelitian.

Variabel penelitian terdiri dari tiga variabel bebas yaitu pendidikan (X1), pelatihan (X2) serta pengalaman mengajar (X3), sedangkan variabel terikat yaitu profesionalisme guru (Y). Teknik pengumpulan data menggunakan metode kuesioner. Indikator pengukuran variabel pendidikan yaitu jenjang pendidikan dan kesesuaian pendidikan dengan pekerjaan. Indikator pengalaman mengajar, terdiri dari masa kerja, tingkat pengetahuan, dan penguasaan terhadap pekerjaan. Indikator variabel profesionalisme guru terdiri dari kompetensi pedagogik, kompetensi kepribadian, kompetensi sosial, dan kompetensi profesional. Prosedur pengumpulan data dilakukan dengan menyebarkan kuesioner kepada semua guru di lima SDLB yang menjadi objek penelitian.

Validitas dan reliabilitas instrumen diuji dengan menggunakan data penelitian. Semua item pertanyaan yang dinyatakan valid dan reliabel selanjutnya digunakan sebagai instrumen pengumpulan data penelitian. Teknik analisis data menggunakan analisis regresi berganda. Uji prasyarat analisis, yaitu uji normalitas, uji linieritas, uji heterokedastisitas, dan uji multikolinieritas. Jika kriteria pada uji prasyarat analisis terpenuhi maka dilanjutkan dengan uji t, uji $\mathrm{F}$, dan koefisien determinasi.

\section{HASIL DAN PEMBAHASAN}

Pengujian hipotesis penelitian menggunakan teknik analisis regresi berganda yang memiliki uji prasyarat analisis, terdiri dari uji normalitas, uji multikolinieritas, uji linieritas, dan uji heterokedastisitas (Ghozali, 2011).

Uji normalitas dilakukan untuk menguji residual berdistribusi normal atau tidak dengan Kolmogorov-Smirnov. Kriteria dari uji normalitas adalah data mengikuti distribusi normal apabila nilai signifikansi pengujian Kolmogorov-Smirnov $(\mathrm{K}-\mathrm{S})>0,05$.

Tabel 1. Hasil Uji Normalitas

\begin{tabular}{cccc}
\hline $\mathbf{N}$ & Statistik K-S & Sig & Kesimpulan \\
\hline 63 & 0.104 & 0.086 & Normal \\
\hline
\end{tabular}

Dari tabel 1, dapat diketahui bahwa semua nilai nilai signifikansi uji KolmogorovSmirnov > 0.05, sehingga dapat disimpulkan bahwa data residual model regresi berdistribusi normal.
Uji prasyarat analisis yang kedua adalah uji multikolinearitas yang dimaksudkan untuk mengetahui apakah diantara variabel bebas tidak saling berkorelasi atau tidak ada hubungan signifikan antara variabel bebas.

Tabel 2. Hasil Uji Multikolinearitas

\begin{tabular}{lccc}
\hline \multicolumn{1}{c}{ Variabel } & Tolerance & VIF & Kesimpulan \\
\hline Pendidikan (X1) & 0.944 & 1.059 & Non Multikolinieritas \\
Pengalaman mengajar (X3) & 0.944 & 1.059 & Non Multikolinieritas \\
\hline
\end{tabular}


Tabel 2 menunjukkan bahwa variabel disiplin kerja, gaya kepemimpinan dan kepuasan kerja memiliki nilai VIF kurang dari 10 dan nilai tolerance lebih besar dari 0,1 sehingga dapat disimpulkan bahwa penelitian ini terbebas dari multikolinearitas.
Uji prasyarat analisis ketiga adalah uji linearitas yang bertujuan untuk mengetahui hubungan variabel bebas dan variabel terikat, apakah memiliki hubungan linear atau tidak.

Tabel 3. Hasil Uji Linieritas

\begin{tabular}{cccc}
\hline $\begin{array}{c}\text { Hubungan } \\
\text { Variabel }\end{array}$ & Nilai F & Sig & Kesimpulan \\
\hline X1-Y & 1.836 & 0.064 & Linier \\
X2-Y & 1.605 & 0.107 & Linier \\
\hline
\end{tabular}

Berdasarkan ringkasan uji linearitas diperoleh hasil hubungan pendidikan, pelatihan dan pengalaman mengajar terhadap profesionalisme guru memberikan hasil linear, karena memiliki nilai signifikansi $>0.05$.

Uji prasyarat analisis ketiga adalah uji heterokedastisitas yang bertujuan untuk mengetahui apakah apakah dalam model regresi terjadi ketidaksamaan variance dari residual satu pengamatan ke pengamatan lain. Hasil uji heterokedastisitas pada Gambar 1 menunjukkan plot data menyebar secara acak dan tidak membentuk suatu pola tertentu atau menyebar di atas dan di bawah angka nol pada sumbu $\mathrm{Y}$. Artinya, model regresi tidak memiliki masalah heteroskedastisitas.

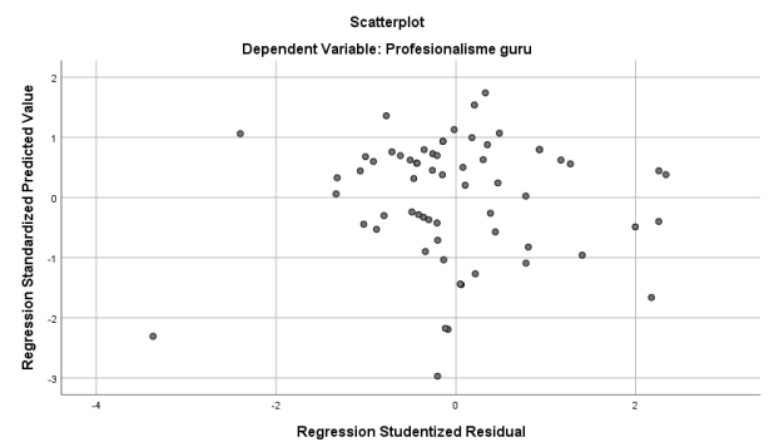

Gambar 1. Hasil Uji Heterokedastisitas

Uji prasyarat analisis telah terpenuhi, kemudian dilakukan analisis regresi linear berganda dengan bantuan program SPSS for windows versi 26 untuk menguji hipotesis penelitian.

Hasil pengolahan data didapatkan hasil pada Tabel 4. Pada tabel tersebut ditunjukkan bahwa ada pengaruh pendidikan dan latihan serta pengalaman mengajar terhadap profesionalisme guru. Hal ini dapat dilihat dari persamaan regresi $\mathrm{Y}=7.785+0.277 \mathrm{X} 1+0.704 \mathrm{X} 2$, berdasarkan persamaan tersebut terlihat bahwa koefisien regresi dari masing-masing variabel independen bernilai positif, pendidikan dan pengalaman mengajar secara bersama-sama berpengaruh positif terhadap profesionalisme guru. 
Tabel 4. Hasil Uji Regresi Berganda

\begin{tabular}{|c|c|c|c|c|c|}
\hline & \multicolumn{2}{|c|}{$\begin{array}{l}\text { Unstandardized } \\
\text { Coefficients }\end{array}$} & \multirow{2}{*}{$\begin{array}{l}\text { Standardized } \\
\text { Coefficients } \\
\text { Beta }\end{array}$} & \multirow[t]{2}{*}{$\mathrm{t}$} & \multirow[t]{2}{*}{ Sig } \\
\hline & $\mathrm{B}$ & Std. Error & & & \\
\hline (Constant) & 7.785 & 3.226 & & 2.413 & 0.019 \\
\hline Pendidikan & 0.277 & 0.096 & 0.229 & 2.890 & 0.005 \\
\hline Pengalaman mengajar & 0.704 & 0078 & 0.717 & 9.057 & 0.000 \\
\hline \multicolumn{6}{|c|}{ Dependent Variable: Profesionalisme guru } \\
\hline \multirow{2}{*}{\multicolumn{6}{|c|}{$\begin{array}{l}\mathrm{R}=0.803 \\
\mathrm{R} \text { square }=0.645\end{array}$}} \\
\hline & & & & & \\
\hline \multicolumn{6}{|c|}{ Adjusted R square $=0.633$} \\
\hline \multicolumn{6}{|c|}{ F hitung $=54.437$} \\
\hline Sig. $=0,000$ & & & & & \\
\hline
\end{tabular}

Hasil uji hipotesis pertama diketahui bahwa koefisien regresi variabel pendidikan terhadap profesionalisme guru sebesar 0.277 (positif), nilai $\mathrm{t}$ sebesar 2,890 dengan tingkat signifikasi t sebesar 0.005 ( $\mathrm{sig}<0.05$ ), sehingga dapat dinyatakan bahwa variabel pendidikan berpengaruh positif terhadap profesionalisme guru. Berdasarkan hasil pengujian tersebut dapat dikatakan bahwa semakin baik pendidikan guru, maka profesionalisme guru juga semakin baik. Dengan demikian, hipotesis pertama dapat diterima.

Temuan penelitian ini sejalan dengan penelitian sebelumnya bahwa tingkat pendidikan berpengaruh positif signifikan terhadap kompetensi profesional guru. Pendidikan yang memadai akan membuat manusia mempunyai kesempatan memperbaiki kehidupannya dan lebih terbuka menerima inovasi, memperluas cakrawala dan mempertajam pemahaman terhadap berbagai fenomena (Eliyanto \& Wibowo, 2013).

Hasil uji hipotesis kedua diketahui bahwa koefisien regresi variabel pengalaman mengajar terhadap profesionalisme guru sebesar 0.704 (positif), nilai t sebesar 9.057 tingkat signifikasi t sebesar 0.000 (sig < 0.05), sehingga dapat dinyatakan bahwa variabel pelatihan berpengaruh positif terhadap profesionalisme guru.
Berdasarkan hasil pengujian tersebut dapat dikatakan bahwa semakin banyak pengalaman mengajar guru, maka profesionalisme guru juga semakin baik. Dengan demikian, hipotesis ketiga dapat diterima.

Temuan penelitian ini selaras dengan penelitian sebelumnya bahwa pengalaman mengajar berpengaruh positif dan signifikan terhadap profesionalisme guru (Qomariyah, 2016). Pengalaman mengajar merupakan salah satu faktor yang sangat menentukan keberhasilan dalam pendidikan. Pengalaman mengajar dalam hal ini adalah selang waktu menjadi guru. Lamanya tugas sebagai seorang guru akan memberikan pengalaman yang berbeda antar guru yang satu dengan guru yang lainnya (Roza, 2016).

Hasil uji hipotesis ketiga diketahui bahwa nilai $\mathrm{F}$ sebesar 54.437 dengan tingkat signifikasi $\mathrm{F}$ sebesar 0.000 (sig < 0.05). Hal ini berarti ada pengaruh pendidikan, pelatihan, dan pengalaman mengajar terhadap profesionalisme guru. Berdasarkan kesimpulan tersebut dapat dikatakan kecenderungan peningkatan kombinasi pendidikan, pelatihan, dan pengalaman mengajar, maka akan diikuti peningkatan profesionalisme guru. Dengan demikian, hipotesis ketiga dapat diterima. 
Tabel 5. Kontribusi Pengaruh

\begin{tabular}{lccc}
\hline Variabel & $\begin{array}{c}\text { Koefisien } \\
\text { beta }\end{array}$ & $\begin{array}{c}\text { Korelasi } \\
\text { product } \\
\text { moment }\end{array}$ & $\begin{array}{c}\text { Besar } \\
\text { pengaruh }\end{array}$ \\
\hline $\begin{array}{l}\text { Pendidikan } \\
\begin{array}{l}\text { Pengalaman } \\
\text { mengajar }\end{array}\end{array}$ & 0.229 & 0.399 & 0.091 \\
\hline & 0.717 & 0.772 & 0.554 \\
\hline
\end{tabular}

Besar pengaruh masing-masing variabel bebas dapat dapat diketahui dari perkalian antara koefisien beta dengan korelasi zero-order (korelasi product moment) (Lufri, 2004). Pada Tabel 4 diketahui nilai koefisien determinasi $\mathrm{R}$ square $=0.645$, artinya pengaruh pendidikan, pelatihan, dan pengalaman mengajar secara simultan terhadap profesionalisme guru sebesar 64.5\%. Pada Tabel 5, kontribusi masing-masing variabel bebas terhadap profesionalisme guru yaitu pendidikan sebesar $9.1 \%$ dan pengalaman mengajar sebesar 55.40\%. Hasil tersebut menunjukkan bahwa, pengalaman mengajar memiliki pengaruh paling besar terhadap profesionalisme guru SDLB di Kabupaten Kudus.

Dalam profesi guru, guru diharapkan meningkatkan kualitas pengajaran, kompetensi, strategi pengajaran, dan mengetahui perkembangan keilmuan (Aldahmash, et al, 2019). Siswa sekolah luar biasa membutuhkan partisipasi guru dalam kegiatan kelas dan berupaya membuat kemajuan dalam perkembangan siswa (Pérez, Llanos, \& Guasp. 2017).

Pendidikan mempunyai peranan penting dalam upaya meningkatkan kualitas sumber daya manusia, termasuk para guru sebagai pendidik. Guru profesional berperan penting dalam proses belajar mengajar untuk meningkatkan hasil belajar siswa (Tanang \& Abu, 2014). Kualifikasi pendidikan profesional guru berpengaruh signifikan pada sikap perilaku dan kegiatan belajar oleh guru. Ada pengaruh yang signifikan profesionalisme guru terhadap prestasi siswa (Bakar, 2017).

Pendidikan khusus merupakan pendidikan bagi peserta didik yang memiliki tingkat kesulitan dalam mengikuti proses pembelajaran karena kelainan fisik, emosional, mental, intelektual, sosial, dan/atau memiliki potensi kecerdasan dan bakat istimewa (Firmansyah \& Widuri, 2014). Oleh karena itu, kompetensi serta pengetahuan yang dimiliki guru sangat membantu guru dalam memberikan layanan bagi peserta didik. Sikap tersebut merupakan salah satu bagian dari profesionalisme guru, seperti dijelaskan Lubis (2016) bahwa profesionalisme guru sebagai kualifikasi kemampuan tenaga pengajar dalam merencanakan, mengelola, mendiagnosis, menilai proses dan hasil belajar.

Guru yang memiliki kemampuan yang baik dalam bidangnya akan mampu melaksanakan tugasnya dengan baik dan mampu mengatasi permasalahan yang muncul saat pelaksanaan kerja. Hal ini akan mendukung pekerjaan guru, sehingga profesionalisme guru menjadi lebih meningkat. Peningkatan pengalaman, pengetahuan, dan keterampilan, partisipasi dalam pembelajaran profesional berhubungan dengan tercapainya tujuan pembelajaran (Louws, et al, 2017)

Pengalaman guru dalam mengajar sangat berperan penting bagi perilaku guru dalam mengajar. Studi yang dilakukan (Gore, et al, 2017) menjelaskan bagaimana dukungan pembelajaran guru berdampak positif pada kualitas pengajaran dan moral guru. konsep profesionalisme guru dalam pendidikan telah diteliti dalam hubungannya dengan banyak variabel lain, salah satunya faktor pengalaman guru (Saberi \& Sahragard, 2019). Pengetahuan dan pengalaman sebelumnya yang dipersepsikan guru akan membentuk perilaku dalam tugas profesional, membimbing dan memberikan pembelajaran bagi peserta didik dengan kebutuhan khusus (Rudiyati, Pujaningsih, \& Mumpuniarti, 2017). Guru yang memiliki banyak pengalaman mengajar akan lebih mudah memahami perilaku siswa. Kondisi tersebut dapat memudahkan tugas guru dalam mendidik siswa, 
selanjutnya hal ini akan meningkatkan profesionalisme guru.

Guru yang berpengalaman akan dapat memahami peserta didiknya di dalam proses pembelajaran dan interaksi sehari-hari agar guru mampu memahami pula kebutuhan serta keunikan tiap peserta didik anak berkebutuhan khusus guna membimbing dan membantu mengembangkan potensi tersebut dengan maksimal (Setianingsih, 2018). Melalui pengetahuan yang dimiliki tersebut, guru akan memiliki sikap positif dalam memandang keberadaan anak berkebutuhan khusus di sekolah, guru akan mampu memahami karakteristik siswa dan berusaha membimbing sesuai kebutuhan siswa. Hal ini menunjukkan sikap profesional yang ditunjukkan oleh guru SDLB. Seperti disebutkan Roza (2016), bahwa guru yang profesional adalah guru yang berkualitas, berkompeten, dan guru yang dikehendaki untuk mendatangkan prestasi belajar serta mampu mempengaruhi proses belajar siswa yang nantinya akan menghasilkan prestasi belajar siswa yang lebih baik.

Aulia dan Widodo (2016) menjelaskan melalui pengalaman guru juga belajar mengembangkan dan memperbaiki diri menjadi lebih baik, karena sesuai dengan teori kontruktivisme belajar merupakan proses mengasimilasi dan menghubungkan pengalaman atau bahan yang dipelajarinya dengan pengertian yang sudah dimiliki, sehingga pengertiannya menjadi berkembang. Sehingga dengan pengalaman mengajar guru dapat meningkatkan pencapaian standar kompetensi profesional guru.

Sikap profesional guru dipengaruhi oleh berbagai faktor. Seperti dijelaskan Kasirah (2011) bahwa kompetensi individu dapat terbentuk karena adanya potensi bawaan dan lingkungan sekitar. Teori yang mendasari pemikiran ini adalah teori konvergensi yang dipelopori oleh William Stren. Menurut teori ini, hasil dari kerja sama antara hereditas (pembawaan) dan environment (lingkungan). Tiap individu merupakan perpaduan atau konvergensi dari faktor internal (potensi-potensi dalam diri) dengan faktor eksternal (lingkungan termasuk pendidikan). Hal ini sesuai dengan hasil penelitian ini yang menunjukkan profesionalisme guru dipengaruhi oleh faktor pendidikan dan pengalaman dalam mengajar guru yang terbentuk dari lingkungan sekolah. Guru yang profesional diharapkan mampu menyelenggarakan pendidikan yang berguna bagi anak yang membutuhkan layanan pendidikan luar biasa.

\section{SIMPULAN DAN REKOMENDASI}

Berdasarkan hasil analisis data penelitian, maka dapat disimpulkan bahwa pendidikan, pelatihan serta pengalaman mengajar berpengaruh signifikan terhadap profesionalisme guru SDLB di Kabupaten Kudus. Hasil uji koefisien determinasi $\left(\mathrm{R}^{2}\right)$ sebesar 0.645 menunjukkan bahwa besarnya pengaruh pendidikan, pelatihan dan pengalaman mengajar terhadap profesionalisme guru adalah $64.5 \%$, sedangkan sisanya $35.5 \%$ dipengaruhi variabel lain diluar penelitian. Kontribusi masing-masing variabel bebas terhadap profesionalisme guru yaitu pendidikan sebesar $9.1 \%$ dan pengalaman mengajar sebesar 55.4\%.

Guru SDLB dapat meningkatkan profesionalisme dengan meningkatkan pendidikan formal yang lebih tinggi. Dinas Pendidikan dapat memberikan kesempatan bagi guru untuk mengikuti pelatihan untuk menambah keterampilan guru. Guru dapat menambah pengalaman mengajar dengan selalu mengamati perkembangan anak didik. Pihak sekolah hendaknya melakukan pengawasan secara berkelanjutan agar dapat memantau perkembangan kompetensi guru.

\section{DAFTAR PUSTAKA}

Annisa, M., Nanna, W., Sofya, A., \& Kusnadi, D. (2019). Pengembangan Profesionalisme Guru Melalui Pelatihan Pengembangan Tes, Konstruksi dan Analisis Butir Soal Di Wilayah 2T. LENSA (Lentera Sains): Jurnal Pendidikan IPA, 9(2): 46-54.

Aldahmash, A., Alshamrani, S.M., Alsarrani, F.S. (2019). Research Trends in In-service Science Teacher Professional Development from 2012 to 2016. International Journal of Instruction, 12(2) 163-178. 
Aulia, N. \& Widodo, J. (2016). Pengaruh Pengalaman Mengajar Dan Etos Kerja Terhadap Kompetensi Profesional Guru Produktif Pemasaran SMK Bisnis dan Manajemen di Kota Semarang. Economic Education Analysis Journal, 5(3): 10201033.

Bafadal, I. (2008). Peningkatan Profesionalisme Guru Sekolah Dasar. Jakarta: Bumi Aksara.

Bakar, R. (2017). The influence of professional teachers on Padang vocational school students' achievement. Kasetsart Journal of Social Sciences, 39: 67-72.

Eliyanto, \& Wibowo, U. (2013). Pengaruh Jenjang Pendidikan, Pelatihan, Dan Pengalaman Mengajar Terhadap Profesionalisme GURU Sma Muhammadiyah Di Kabupaten Kebumen. Jurnal Akutabilitas Manajemen Pendidikan, 1(1):34-47.

Firmansyah, I \& Widuri, E.L. (2014). Subjective Well-Being Pada Guru Sekolah Luar Biasa (SLB). EMPATHY, Jurnal Fakultas Psikologi, 2(1):1-8.

Ghozali, I. (2011). Aplikasi Analisis Multivariat dengan SPSS 19. Semarang: Badan Penerbit Universitas Diponegoro.

Gore, J., Lloyd, A., Smith, M., Bowe, J., Ellis, H., \& Lubans, D. (2017). Effects of professional development on the quality of teaching: Results from a randomised controlled trial of Quality Teaching Rounds. Teaching and Teacher Education, 68: 99-113.

Kasirah, I. (2011). Kompetensi Pedagogis Guru PLB Dalam Meningkatkan prestasi Belajar Anak Berkebutuhan Khusus. Perspektif Ilmu Pendidikan, 24: 163173.Komalasari, Febyana Putri. Profesionalisme Guru Ditinjau Dari Pendidikan Dan Latihan Serta Pengalaman Mengajar Di SMP Negeri Se-Kecamatan Delanggu Tahun 2014. Prosiding Semiar Nasional Pendidikan Ekonomi \& Bisnis, Universitas Sebelas Maret Surakarta.
Lubis, P. (2016). Pengaruh Profesionalisme Guru Dan Iklim Kerja Terhadap Efektivitas Kerja Guru. TANZHIM Jurnal Penelitian Manajemen Pendidikan, 1(2): 19-29.

Lufri. (2004). Sumbangan Efektif Berpikir Kritis, Persepsi, Minat dan Sikap Terhadap Hasil Belajar. Jurnal pendidikan Triadik, 1(8): 167-178.

Louws, M. L., van Veen, K., Meirink, J.A., \& van Driel, J.A. (2017). Teachers' professional learning goals in relation to teaching experience. European Journal of Teacher Education, 40(4): 487-504.

Pérez, P., Llanos, M.N., \& Guasp, J.J.M. (2017). Inclusive practices: the role of the support teacher. Aula Abierta, (46) 49-56

Pratama, L.D. \& Lestari, W. (2020). Pengaruh Pelatihan Terhadap Kompetensi Pedagogik Guru Matematika. Jurnal Cendekia: Jurnal Pendidikan Matematika, 4(1): 278-285.

Prayitno, R. (2019). Pengaruh Tingkat Pendidikan dan Pengalaman Mengajar terhadap Kompetensi Profesional Guru Pada Mata Pelajaran IPS di SD SeKecamatan Buntu Batu Kabupaten Enrekang. Phinisi Integration Review, 2(1):81-90.

Qomariyah, S. (2016). Pengaruh Kualifikasi Pendidikan dan Pengalaman Mengajar Terhadap Profesionalisme Guru Dalam Pembelajaran IPA di SD di Gugus II Distrik Nabire. Jurnal Ilmu Pendidikan Indonesia, 4(3): 26-34.

Rahmawati, S., Natsir, S., \& Moelyono, S. (2015). Pengaruh Pelatihan, Pengalaman Mengajar dan Kompensasi terhadap Profesionalisme Guru di SMK Negeri 3 Palu. e-Jurnal Katalogis, 3 (12): 67-75.

Roza, J. (2016). Pengaruh Pelatihan dan Pengalaman Mengajar terhadap Profesionalisme Guru Madrasah Aliyah Negeri (MAN) Di Kabupaten Tanah Datar. Jurnal al-Fikrah, 4(2):134-146.

Rusdin. (2017). Pendidikan Dan Pelatihan Sebagai Sarana Peningkatan Kompetensi Guru Di SMP Negeri 02 Linggang Bigung. Jurnal Administrative Reform, 5(4): 200-212. 
Setiawan, D. (2018). Pemberdayaan Guru dalam Meningkatkan Kualitas Pembelajaran di SLB. Indonesian Journal of Education Management and Administration Review, 2(1): 177-181.

Setianingsih, E. S. (2018). Penerimaan Dan Sikap Guru Terhadap Keberadaan ABK Di Sekolah. Empati, Jurnal Bimbingan dan Konseling, 5(1): 34-46.

Sahari. (2015). Pengaruh Pendidikan, Pelatihan, dan Pengalaman Mengajar terhadap Profesionalisme Guru Di SMAN I Likupang. Jurnal Pendidikan Islam Iqra', 9(1):62-86.

Sulfemi, W.B. (2015). Kemampuan Pedagogik Guru. Prosiding Seminar Nasional STKIP Muhammadiyah Bogor Tahun 2015, 1(1): 75-86.

Rudiyati, S. \& Pujaningsih, M. (2017). Teachers' Knowledge and Experience Dealing With Students With Learning Disabilities in Inclusive Elementary School. Advances in Social Science, Education and Humanities Research (ASSEHR), (66) 272-278

Saberi, L \& Sahragard, R. (2019). Designing and Validating Teachers' Professional Development Scale: Iranian EFL Contexts in Focus. International Journal of Instruction, 12(1) 1610-1626.

Tanang, H \& Abu, B. (2014). Teacher Professionalism and Professional Development Practices in South Sulawesi, Indonesia. Journal of Curriculum and Teaching, 3(2):25-42.

Undang-Undang Nomor 20 Tahun 2003 tentang Sistem Pendidikan Nasional, pasal 1 ayat (1). 